\title{
Cultural Factors That Influence the Intervention with Latin-American Minors
}

\author{
Reina Castellanos Vega \\ Faculty of Education, University of Zaragoza, Zaragoza, Spain \\ Email: rvega@unizar.es
}

Received 24 February 2015; accepted 13 April 2015; published 14 April 2015

Copyright (C 2015 by author and Scientific Research Publishing Inc.

This work is licensed under the Creative Commons Attribution International License (CC BY).

http://creativecommons.org/licenses/by/4.0/

(c) (i) Open Access

\section{Abstract}

This article tries to announce the cultural factors that influence the intervention with LatinAmerican minors. For it there offers a general vision of the situation that the minors present in some countries of Latin America (Colombia, Ecuador and Dominican Republic) due to the fact that according to information of the last poll of the National Institute of Statistics, in Spain they represent the second group of immigration and if one speaks about minors have a major presence in Spanish soil being outlined the band of age between the 10 to 19 years. It is a study of descriptive character; the interview is in use to key informants who come from Latin America especially from the renowned countries previously. In this investigation, the situation of the minors is described in risk in his native land, the familiar models inside the Latin culture, the role of the man and the woman, the migratory process, the meeting with the culture of reception, the reasons and motives that take these young persons to the formation of gangs, the situation that the same ones present in the Spanish company and which are the cultural guidelines that can influence at the moment of attend users of Latin-American origin. One has thought that the young persons form gangs to find the fondness and the attention, often denied in the home or to be protected from other gangs; on the other hand, it highlights an increase of the feminine headquarters where there is related to the belief increasingly widespread that the children are a private cost that must be taken up office basically for the women; in addition, the young persons observe his parents with the modal of economic but not emotional stability.

\section{Keywords}

Social Exclusion, Third World, Gangs, Cultural Factors

\section{Introduction}

The Latin-American women are those who emigrate more inside the group and a major presence of the same ones stands out inside the total of women who have emigrated to Spain in 57\%. Many of them are mothers who 
at first leave his children in the native land to the care of relatives and friends, but his desire is to regroup them in the country of reception. Nowadays, the Latin-American minors are the first group with major presence in Spanish soil with a total of 220,140 and the band of age stands out between 10 years to 19 years (INE, 2011).

Later there is announced a general vision of the situation that the minors present in some countries of Latin America (Colombia, Ecuador y Dominican Republic). One refers to these same due to the fact that it is foreigners' major presence in Spain of this origin, also his migratory process, the meeting is outlined with the culture of reception, the reasons and motives that take these young persons to the formation of gangs and which is the situation in the country recipient.

\subsection{Situation of the Minors in Risk in His Native Land}

Inside the legal basic frame of Colombia, Ecuador and Dominican Republic, one thinks that the minimal age for the work is 14 to 15 years, the obligatory education is from 5 years to 15 or 16 years, as for the penal responsibility, the civil majority and the age for the marriage is at the age of 18 Colombia (Civil Colombian Code, 2012; Civil Ecuatorian Code, 2011) and 15 years women y 16 years men in Dominican Republic (Embassy The United States in Dominican Republic, 2015).

The juvenile Latin-American population presents a series of difficulties in areas as the education, the geographical location, the scanty formation in sexual health and the violence where his study will help us to understand the situation.

In Latin America, the poverty rate is $33.1 \%$ and $13.1 \%$ are homeless or living in extreme poverty (CEPAL, 2010) the youth population $17.9 \%$ are in extreme poverty, total more than 32 million children (CEPAL/UNICEF, 2010) they live on the street, most are drug addicts from heroin and the common glue. Key informant: “The children who live in the street him are called by us gamines or paupers in Colombia and in Peru there are called they canillitas”.

With regard to the education, they find differences between the public centers and the private centers. The families with economic resources and certain social position take his children to educational private centers (lyceums, catholic centers, ...) being the formative comparable level to the European. In reference to the public some centers they present a low coverage of the basic primary education for the lack of human, material resources and of infrastructure, generating high indexes of illiteracy in the population.

On the other hand, many minors are out of the educational system for economic reasons and have to work for the daily sustenance of family, being the only alternative that they have to survive (Martín, 2007). It is observed minors between 5 and 17 years working already be in the domestic service, as bootblack, etc., realizing days of 48 h/weekly, they have emigrated from the rural sector to the cities. Key informant: "My aunt said to my mother that he needed a girl in order that it was helping him in house and was taking care of the children in exchange would give myself education, housing, food and it was like that, this weekend we travel to Bogota, he was 9 years old”.

In the urbanization, Latin America is outlined for his social differences, there is distinguished between whom it is rich and the one who is poor, a feature that also one reaffirms in the city according to the place alive where, in the southern part, zone destined for the poor, but if it is lived in the northern part, zone destined for the rich ones, east and west, for the middle class that tends to disappear.

As for the sexual health of the Latin-American young persons, it is characterized for having sexual relations to very short age for the men 13.4 years and for the women 14.8 years. In Ecuador, they initiate the sexual life at the age of 10 and 12. The pregnancy in the adolescence continues being frequent in Latin America of every thousand registered pregnancies 80 give each other in young women from 15 to 19 years, almost more of the triple one of the rate in countries developed (CEPAL, 2011).

It thinks that $40 \%$ of the pregnancies is not planned and are a consequence of not using contraceptive methods, his use is realized after having the first son, of using inadequate methods or of faults on having used it due to the lack of reliable information about reproductive health where the reticence between many of the community and family parents to providing sexual education is common and they do not do it for fear of an unworthiness of the moral values and taboo is considered to be a topic. Key informant "In our country in secondary there is a subject that was called behavior and health, the parts of the body are announced and already it is, up to the point that when it comes to Spain and the doctor I ask myself that every all that was coming to myself the rule, I said to him $x$ days and it could only looking, it took a calendar and asked me of the last rule ¿When did it come to 
you? ¿Which was last day?, certainly I became red, because it did not know the most basic thing, since it is this and having top studies”. Also there are cases where the poverty of some families and the possibility of gaining easy money, do that some teenagers are induced to support a sexual early activity (Rodríguez, 2009).

In relation to the violence, the increase of the same one in the juvenile population owes to that traditionally, there exists the culture of the consumption of alcohol, use of firearms, and also, the diffusion in the mass media of the violence in which the population is immersed.

The armed groups that exist in some countries, especially Colombia, where they recruit minors and generate displacements of the population of the rural zone to the urban zone, increasing this way the poverty. Another aspect that it is necessary to stand out is the influence of the model of North American gangs.

\subsection{Gangs: Modalities, Reasons, Motives, Signs and Intervention}

The North American gangs on having exported his practices and structures to the Latin-American countries, these juvenile groups have different modalities: a) "Gangs" that are groups of 3 or 4 members who meet in a neighborhood; b) "Cities" that are groups that have connection with other gangs of her take care; c) "Nations" are gangs that have dialog with other groups racketeers but in different cities of the country; d) "the empires” the gangs have dialog and connection with other gangs that are in different countries. The women's presence is minority, nevertheless, those who are there do not take decisions and do not decide the course that must take the gang, only they are the balsam of the gang for his humanism and the expression of affection, in addition, normally the families tend to know or deny the belonging or entail of his children to the bands or gangs.

The reasons that lead these young persons to joining to the juvenile gangs are the familiar disintegration (divorces, separations, types of upbringing in the families and immigration of the parents), the increase of the consumption of drugs inside the gangs, the lack of a public politics for the free time of the young persons and of opportunities from the labor point of view, the school absenteeism and the poverty carries to extremes (PDH, 2004; Santacruz, 2001; World International Vision, 2001).

With regard to the type of upbringing, there are investigations Sohrabi and Hasani (2007) the teenagers who have permissive parents enjoy a high quality of life. On the other hand, the teenagers who have authoritarian parents enjoy a quality of low life, situation that one presents in the country of reception, due to the fact that the parents want to take the same style of upbringing of his native land, but since to see in previous paragraphs, this type of upbringing the young persons do not accept it.

The motives that do that the young person feels attracted by the gangs, are because they find the loyalty, the love, the protection and the dedication that they do not have in his family, the search of sense, of respect and power, to be protected from other gangs, for his low aspirations and desires of achievement, are young with school failure and want to obtain easy money, Because of it they are an easy white for the drug-traffickers, are young that cannot occupy his time, do not feel as productive persons, other young persons ignore the commitment contracted on having formed a part of the gangs and finally, the influence of the way in which it lives (relatives and friends are members of gangs).

The signs that they can find and that reveal that these young persons take part in gangs are: to have big quantities of money and costly articles that cannot explain, being this paragraph, the most appetizing for the Latin American since they like to have the last thing in technology, generating for the others an image of which it has "money", also, they have problems of attitude with the teachers, parents and other figures of authority, because to show or to have a challenging attitude helps to raise the reputation of a member of the gang, and to be accepted by the same one.

A third sign, it is the presence of graffiti in his quarter, books, clothes, sports footwears, etc., the use of colors allusive or similar to the members' gown of gangs, necklaces, watch-straps, etc., for example: the utilization of the yellow one and the black that they are colors used by the Latin kings ó red, white and blue colors used by the ñetas or the Dominican Dont Play, also we can observe the presence of mutilation in the body, tattooes, scars, etc., the use of hand signs to communicate and the language triz or slang of the gangs. Key informant: "To my friend if frog has gone out for me I they say: that happens men! Calceto!, if I like something I say: bacano! Or if it is my close friend, I say to him: my key, my parcero!”

These juvenile gangs devote themselves to the traffic and consumption of drugs, kidnappings, you fight between groups, some sound assassins use the extortion and intimidation, realize thefts, assaults, robberies, in some occasions, children/girls use from 6 to 12 years due to the fact that the legislation treats them otherwise. It 
is known that in Pereira in the year 2006, the wives of the racketeers chose to do the "Strike of crossed legs". In order to reduce the indexes of violence on having deprived his husbands of sexual relations. A Study of the Secretary of Security of Pereira's Town hall thought: "That the activity preferred by these is to do the love, and that are in the delinquency not for economic need, but for a modal of power and sexual seduction” (Lozano, 2006).

Nowadays, some organisms are employed at the prevention and rehabilitation of the gangs, for example, in Dominican Republic is the Central Direction of Managing group in Conflicts with the law, they give courses in colleges and elaborate material to guide the parents and teachers before how to act, what to do, what signs they can find, since anticipate the formation of gangs.

In Ecuador, DINAPEN is (National Direction of Police Specialized in Children and teenagers) and in Colombia, one of the organizations that works with young ex-racketeers is IDIPRON (Institute Distrital for the Protection of the Childhood and the Youth, 2008) in this Institute the program exists trapeze artists there carry out workshops of electricity, mechanics, computer science, impression, Design, carpentry, bakery and pastry shop for his own consumption and exterior sale, make bicycles that then are offered to other poor boys by the equivalent to 15 Euros. Also the project in the national radio and the group of Snail Junior, where 640 minors have produced radial pieces and exercise his right to the participation and the expression with the motto "You have the microphone". It shows the voices of the children, his ways of seeing the world, the topics of interest, they announce projects and regulations on the infancy and the youth.

\subsection{The Familiar Organizations}

The family is very important in the countries of Latin America, it thinks that it is the place where it is possible to find guide and orientation. Nowadays, is observed an increase of the feminine headquarters and there is related to the belief increasingly widespread that the children are a private cost that must be taken up office basically for the women. Nevertheless, the masculine headquarters associate not only with the structure of the power inside the family but with the bosses of property and possession.

As aspects valued like positive in the socialization and the conviviality in the homes with feminine headquarters: a) minor exhibition to violence and mistreatment inside the familiar core; b) the sexual division breaks, children and girls take part more in the capture of decisions; c) certain freedom in order that there develops a feminine modal of autonomy and strength for the daughters and d) destine his resources to the well-being of the group, situation that one does not present if the headquarters are masculine (Rico, 2001).

In the relations of pair a limited role exists in every sex, for the woman it is to be responsible for his home, to take care of his children, of his pair and of his parents in the oldness, in addition, the woman acquires an identity depending on the man, with attitudes of submission and sacrifice for the family, looks for the safety, stability and protection of the man. Key informant: "we go on from the hands of the father to the hands of the husband".

With regard to the role of the man, the emotions are controlled across the weeping (it are considered to be something of girls) and "they are authorized in order that they dominate, be more aggressive and strong and form his virility excluding the girls and the homosexuals", educated to fulfill the role of "man of the house", protector and supplier in the home, figure of authority that he enjoys besides certain privileges and freedoms to the detriment of the woman, in some cases, it does not make the woman a participant of the obtained income (Observatory of Matters of Kind, 2004) Key informant: "My husband every eight days was going to be played the yew (typical game of Colombia) by his friends of the work and was coming tomorrow at three o'clock whistling in order that it was opening the garage him and if you were not getting up it could throw the door of the house, without problem and to avoid what they will say, was the whole awake night".

In Latin America, the following familiar models exist: a) traditional model where father is a supplier and mother does not work and takes care of his children, nowadays, only $36 \%$ of the families they answer to the same one; b) model of extensive family, it is in use as strategy of survival for the care of the children and the distribution of tasks and c) model of single-parent family, is characterized when the mother is alone has three or five children and coexists with the stepfather of shift.

In the last years, is observed that because of the immigration many young persons stay to the care of uncles, grandparents, familiar and up to of neighbors, contracts and informal agreements are realized, that is to say, there is no a legal document that indicates the legal responsibility of the same ones and, to slant, of the remittances that are sent monthly, these young persons have all his material needs covered.

But they have affective lacks, generating consequences as: under school performance, school absenteeism, 
problems of drugs and/or alcohol, gangs, precocious pregnancy, cases of suicide, deterioration of the affective bows... In the main are families separated. Key Informant: "when the visa went out for me to come to Spain, I said to my neighbor, I do not have anybody in spite of whom leaving my children is it possible that one could take care of them? And she said to me that there was no problem that would take care of them in exchange he would send every month money for the expenses and for what the children needed”.

\subsection{Description of the Migratory Process}

In Latin America the social inequality exists and prevails, where there is distinguished the high class of the low class and the middle class tends to disappear for it they want to emigrate to recover his social status. As for the politics only they are and certain traditional families can accede, there are high places levels of corruption, the unemployment is high and is absent perspectives for the new generations.

In Spain, the immigrant Latin population is not associated with the strict sense of the poverty, many of them belong to the middle class, average - discharge and have a certain degree of educational level.

The way of financing his trips they do it for legal route and others, for illegal route. For legal route across the visa already be of studies, for work, for familiar regrouping or for quota and for illegal route across the networks of persons' illegal traffic, where the falsifications are in use in the main. Key informant: "I came with the letter of invitation of my aunt, she I pay the ticket to myself and I entered as tourist Spain”.

The migratory process consists of two steps: The First step, a progenitor emigrates, in the main more women emigrate that men, due to the fact that they think that they have major possibility of finding a work and having the idea of working a time, helping to his family and to be established and the second step, it is to assemble money to regroup to his family in his new place of residence. Key informant “There are men's cases that have returned to the country because the man in Spain has it more difficult to find work. One woman can find anything, for example, in the domestic service".

In the main the immigrants Latin-Americans, come to Spain by air, establish the contact and his residence with the relatives and friends who live here, are they who help them to seek for work, to request the sanitary card and to realize the steps of census or it happens opposite cases with it this key informant reports "The work that I have found was the one that my aunt offered me, taking care of his son, but without papers, without insurance and without he pays" "He was Thinking that I would treat myself well, but it was to come to house and it did not have right to ignite the heating in winter, because he was saying that it was spending very much, for the food was giving myself the surpluses. He threw me of house and the only person who helped me was an Argentina".

\subsection{The Meeting with the Culture of Reception}

The minors confront the separation of his core of relatives and friends of his place of origin. In many cases and during the initial phase they see reduced in a significant way his affective horizon. They are minor that happen a lot of time alone, due to Performance of several employments of his parents, it is calculated that, approximately, a third of the Latin young persons they live with one of the progenitors, and that 36.4\% spends more than 6 hours only every day (Ramo \& Meléndez, 2012).

On the other hand, the parents in many cases meet exceeded in the education of his children, (many of them they did not correct his evil behavior with your grandparents and relatives in the native land) and this situation appears more in the teenagers, on having had to face situations where the minors express a rejection towards the culture and the customs of origin, which they try to transmit, in addition, his children coexist with the rejection of the culture that receives, and medium-term the academic perspectives and labor expectations suffer an adjustment to the reality that they makes a detour. Key informant "I can say that I have received badly I treat on the part of my own family, it was living in a few conditions worse than in my country".

With regard to the previous thing, many young persons shelter in bands for: a) to look for the protection on having seen that they do not give good results in the studies and find the rejection in the educational centers and b) to recover a "identity badly definite" that becomes diffuse when one emigrates abroad, where the language, the etnia or the culture in general, they press the young persons with problems to joining bands which raison d'être has been traditionally the violence and the drugs (Soriano, 2008).

With regard to the previous thing Mustafa et al. (2011) "The parents play an important paper in the change of the quality of life and mental health of the children” really are observed at present situations of mental health in 
Latin-American young persons who have been in his countries they have presented difficult situations with his parents and families, emigrate and there takes place a conclusion of decompensation of his mental health that the own teenagers it do not understand and know the direction that they can take, they are teen that they do not know if they are from the country of reception or from the native land.

\subsection{Cultural Guidelines}

Influence of the migratory process, the project of life of the Latin-American immigrants is to come to Spain with the exposition of working a limited time (5 years approximately) and to return to the native land with the accumulated money. Projects of medium-term stay consider to find as remunerated well work and cheap housings; to save everything possible, even doing courts in the budget for the food, the leisure, the clothes etc., to pay his debts and to support his relatives in origin. The long-term projects, they relate to the native land since it is to construct a house, to do investments, to acquire area in property, to buy goods of long duration for the personal use or of the family.

In the familiar cores in which both parents have emigrated, parents - children spend several years of not conviviality. For these minors, the parents are a modal of economic but not emotional stability. In many past cases 5 years, the will of return turns in "ideally of return"; the project of life, especially if a familiar regrouping has taken place, is centralized in Spain.

If one speaks about the integration in the company of reception, at the social level in the environment of the groups of Latin-American immigrants one sees very disadvantaged by the inability to obtain a conciliation between the labor, familiar and social life. Key informant "Here I work very hardly, in my country it was not doing it. Here one suffers".

Many of the Latin people do not know the possibilities that are to his disposition in the community. The Latin people does not form a closed group where the familiar and local relations are very based and are kept narrow and if they propose them manners of social participation in that there is mixed the leisure and the local, community cooperation, shows an interest and will to take part, likewise, many teenagers of Latin-American origin meet between equal in park or squares to happen his free time, this does not mean that the minors belong automatically to violent gangs or are delinquents.

The majority of the Latin people suffer a strong uprooting derived from the multiple cultural differences, from the inability to support forms of life that they are culturally own and provide to them the safety of his identity and at the same time they have to adapt to the new cultural codes of country recipient. Key informant "Here I see that there are many luxuries, there poverty. My way of being is harder now, before it was more sensitively".

In the country of reception, they present difficulties in the interpretation of linguistic codes and in the interpersonal relations: forms of communication that him are foreign (gestures, expressions, manners of beginning a conversation) ways of showing the authority and the power, the levels of personal contact (tone of voice, treatment of Your or You, social hierarchies) Key informant "A common phrase in America Latin persons is 'you give me', when I bought a cream for the face and happened for a box I said to the cashier: give me a bag, please!, even knowing that the bag is paid and it had thought to pay it, the cashier says to me: I do not give her to you, bandage her to you, from this moment I said I will not use any more this phrase and this way it was”.

The conflicts of pair are carried out due to the fact that the migratory process carries that the woman coexists with a social reality of freedom, tolerance and with another legal frame. In many cases this experience uses as reference to the Latin woman to break with this tradition of submission to the man. Key informant "In our company there is a lot of machismo more that here and this carries problems, one comes here to a situation to which one was not accustomed, where the majority of we break with this idea and with the education that has been received, one sees this freedom of being able to break".

On the other hand, a change of roles takes place. The woman learns to have autonomy on aspects of his labor life, social and familiar environment. Here already it does not depend on the approval of the husband to plan his life. Key informant "To come and to see here a woman who has left his husband in house and goes out with his friends is something that hits because in our culture this is seen badly, until already you are living through it later and realize that it is not anything bad, is a company that has his good things. To the good things we are adapting".

Many conflicts come provoked because the man accepts neither the independence of his wife nor the legal protection that endorses it. In extreme cases the threats and aggressions appear before the danger of which his 
wife could re-do his life with other one. Key informant "It gives shame to the woman to a scandal in the street, because the Latin-American man does not have modesty in this sense of forming problems in any place".

The violence of kind, there exists an emotional and sexual abuse. As for the emotional abuse, the majority of the Latin people who emigrate to Spain belong to a middle class, average - discharge, have received an education based on values machists. The idea prevails, according to key informant “you shouldn't wash your dirty linen in public".

The mental health is associated with the authoritarian education, but not with the liberal education. It seems that the authoritarian education inside a dictatorial culture does not generate so many consequences as inside a liberal culture (Dwairy \& Menshar, 2006), Situation that one presents when these women come to a country totally different from the native land.

The women do not differentiate the different types of violence and most of the women only denounces for physical violence. When the woman is insulted or ill-treated verbally few ones they denounce because they do not perceive it as a violence of kind and, still there being physical mistreatment, they do not do it. Key informant "I Deal for violence of kind or ill-treat the woman and the children, in sense as physical mistreatment".

To level of sexual abuse, they come from environments where a certain social tolerance exists towards the illtreatment. Many women are accustomed to support blows and violent attitudes on the part of his pairs, without denouncing the facts. It is in the habit of accepting supporting sexual relations without his assent. Key informant "I have sexual relations with my pair though it does not want it in any occasions, do not want to feel person in charge of whom it has gone away with other one for this situation".

In the intergenerational relations, the parents are not accustomed to managing and allowing so much freedom to his children, it is stretched to an authoritarian education, specially with the teen daughters and the shock it is more well-known in the country of reception, can provoke alterations. On the other hand, in Latin America, the inadequate conducts are corrected using the belt. Key informant: "When they are going to do something that they do not owe, I say to my children: do they want rind of cattle? They already know that it is the belt and calm down”.

In the Latin cultures the children and girls are raised in one or another role of differentiated form, the women are educated for the housekeeping of the home, to be submissive and look for the protection of the men, by tradition the girl's step is celebrated to woman by the holiday of 15 years; in the men they are educated for the work, they have to be hard, support the honor and to defend the integrity from theirs, for this reason, his step is not celebrated up to compliments 18 years.

As for the concept of familiar unit, the parents worry very much for his children (Health, education, supply ...) the children in exchange have to show a deep respect to his parents, to his major ones and to his family. Situation that it changes into the country of reception where the young persons who remained several years in his native land to the care of third parties developing autonomous conducts, once regrouped in Spain under the guardianship of the parents, they react with aggressiveness to the attempts of control.

In the native lands it is considered to be a normal situation that the minor brothers should remain to the care of the major brother (10 - 13 years) and realize the labors of house. Key informant: "The children in Latin America mature very soon due to the responsibilities that have from very small, since for example, to come from the college, to be alone in house, to warm his food and to do the tasks of the college”.

\section{Method}

In this article there want to be announced the different cultural factors that influence the intervention with LatinAmerican minors.

They have been selected at random across contacts of acquaintances and of the request of interview in persons who manage booths of telephone, it has been chosen for it, because it was observed in the zone that they were managed the majority by Latin people and was the nearest way to contact the Latin population. The educational level of the majority of the interviewed ones they were secondary and university.

In this investigation, the interview is in use since it allows to know and to penetrate into the different aspects that intervene in this group. The interview was formed by ten questions related to his nationality, educational level, how it was his migratory process, impression that has of the country of reception, difficulties in the country of reception to cultural standard, personally, educationally, socially, how work, paper of the woman has obtained in Spain, differences in the upbringing of the minors in the native land with the country of reception, if he 
sends remittances to the native land, aims to short, average and long term in the country of reception and they know resources in the country of reception.

\section{Discussion}

According to investigation Ramo \& Meléndez (2012) it refers to the information treated in this article confirming it disoriented that there are the minors who leave his native land and to adapt to the country of reception. The major desire that the Latin-American minors have is to return to his natal country. Some minors who find minimal stability and see that they can go out forward and to touch by the gangs, try to achieve a few top studies in the country of reception and to be able to return to his native land. These minors when origin comes to his country observe that they are not of here not of there, generating a great decompensation in his mental health, elaborated studies Mustafa et al. (2011) and more if we speak about the authoritarian style of upbringing and machist who is the one that prevails in Latin America (Dwairy \& Menshar, 2006; Sohrabi \& Hasani 2007).

It is necessary bear this type of investigations in mind with the purpose of forming social networks that receive these families, previous information offers before regrouping his minor children, the realities with which it is possible to find in cultural, social differences, linguistic, educational drafts and of upbringing, the latter situation that one presents in Spain (not accompanied minors) there are parents that his minor children leave (12 or 13 years) at the expense of his small brothers being cases that go on to social services, but that in the country of reception are normal situations (Collada et al., 2012).

If familiar regrouping exists, it is necessary that the minors in the country of reception form a part of a network of accompaniment end to anticipate the incorporation of the minors in the gangs for the loneliness that they can present for the multiple works that have his parents and the lack of identity, of value of yes same as the accumulation of frustrations to educational and social level due to the differences in the native land with the country of reception (Gómez, 2014).

\section{Results}

In Latin America, the majority of the Latin-American minors have difficulties, risks and lacks in the education, supply, health, distribution of the free time and leisure due to the social inequality that reigns.

In the country of reception, there exist a series of customs and situations that impede the integration and adjustment of the regrouped minors, between them, the forms of communication, the early responsibilities, the dependence of the migratory process of the parents where many of them especially young women and pre-adolescent, did not have will to leave his country and it they yearn, have had to resign the belonging of already consolidated groups, to leave his friendship, boyfriends, girlfriends, colleges... and this supposes realizing a double effort, therefore, they choose for the search of alternative others at the arrival to Spain, motive for meeting between equal and for doing life in the street being a custom very established in the Latin culture where it is lived much more towards out.

Another aspect to stand out, is that the minors observe a contrast with the opposing reality, where the image that they has been transmitted of Spain does not coincide with the reality that they live and want to return due to this shock.

The acculturation, some minors of Latin origin, feel rejected by his immigrants' condition, principally in the educational centers and the expectations of study that had in his place of origin they are truncated on having joined the Spanish school, with all that, a sensation of insecurity provokes them and in some cases it leads to a crisis of identity, being one of the motives for the formation and integration in gangs.

The precarious economic familiar situation, the hard working conditions of the immigrant adult, the lack of attention for problems in the marriage and the scanty time to take a follow-up of the lives of his children, provokes that many traverse the risk of turning of fact into not accompanied minors or under the Spanish perspective into situation of abandonment and offenders of the law.

\section{Conclusions}

Later, they give themselves a series of necessary recommendations to work with minors of Latin-American origin, having in it counts the cultural factors that can influence for his intervention: It is important to recognize the heterogeneity among Latin American youth, according to age, sex, socioeconomic status, national origin, may 
be a point of engagement and confidence if the professional addresses and known aspects of the country, such as food, celebrations, games, locations, etc.

To the newcomers, to contact them the different associations of the own group, in order to favor his expression of feelings, to teach social skills to them, to give information about rules and applicable policies in his new company of reception.

To facilitate a support psicosocial to these immigrant minors and his parents.

To realize workshops of communication for young women, his purpose, to promote the creativity in the resolution of problems that affects them and to his familiar and community environment.

To promote chats between parents and children, due to the fact that in the native land the educational style is authoritarian, but when the parents emigrate, the children have rancor accumulated for having being left and once regrouped they exploit with aggressiveness towards them themselves and towards his progenitors.

To realize informative chats so much to parents and children on different situations where the Latin minors are immersed: Drugs, alcohol, gangs, sex, absenteeism and school failure... For example, the sexual education in the population of Latin-American origin is practically void especially in the teenagers, and is very determined by the popular and religious beliefs. On the other hand they begin to have sexual relations to a very early age; in addition, initially they lack information about the regulation and the use of the different contraceptive methods... it does that I.V.E.'s (Voluntary intervention of the pregnancy) cases and/or early maternity are numerous in young and teen Latin people.

To promote the project development in workshops of radio, television, written press, art, dance, learning of a trade and social works for teenagers, since for example, the accomplishment of contests of music, dance, generating days of game in every neighborhood already be for the children or for the major ones where it is allowed promote the teamwork of autochthonous and foreign persons and preparing the creation of gangs.

Since professionals it is fundamental to avoid in possible any trend to the overprotection of the immigrant Latin-American families. Initially the focus should be on providing information and advice on the resources available to the autonomous community in different areas such as health, education, social, labor, housing, etc. The aim pursued with it, is to make users autonomously avoiding situations of dependency. The purpose that is chased by it is to achieve that they are users with autonomy avoiding situations of dependence.

\section{References}

Bolghan-Abadi, M., Kimiaee, S.-A., \& Amir, F. (2011). The Relationship between Parents' Child Rearing Styles and Their Children's Quality of Life and Mental Health. Journal Psychology, 2, 230-234.

http://dx.doi.org/10.4236/psych.2011.23036

CEPAL ( 2010). Social Panorama of Latin America. United Nations, CEPAL.

CEPAL (2011). Social Panorama of Latin America, Santiago de Chile, Eclac.

CEPAL/UNICEF (2010). Infantile Poverty in Latin America and the Carib. United Nations, CEPAL.

Civil Colombian Code (2012). Recovered of

http://vlex.com.co/tags/descargar-codigo-civil-colombiano-actualizado-3663254

Civil Ecuatorian Code (2011). Recovered of http://es.slideshare.net/Ramon_Piguave/codigo-civil-ecuatoriano-actualizado-hasta-agosto-del-2011

Collada, M., Navascués, R., \& Gómez, J. (2012). Foreign Not Accompanied Minors What Is after the Adult Age? Institutional Repository of Documents, Zaragoza: University of Zaragoza.

Dwairy, M., \& Menshar, K. E (2006). Parenting Style, Individuation, and Mental Health of Egyptian Adolescents. Journal of Adolescence, 1, 103-117. http://dx.doi.org/10.1016/j.adolescence.2005.03.002

Gómez, J. (2014). Immigrant Families in Spain: He Structures Sociodemográfica, Roles of Kind and Cultural Guidelines of the Teen Children. Journal Papers of population, 80, 87-118.

Institute Distrital for the Protection to the Childhood and Youth (IDIPRON) (2008). Motive That They Lead the of Bogotá Young Persons to the Entail of Gangs Criminal. Bogotá: IDIPRON.

Lozano, P. (2006). The Women of More than 100 Racketeers of Colombia Initiate a Sexual Strike against the Violence. http://elpais.com/diario/2006/09/13/sociedad/1158098407_850215.html

Martín, P. et al. (2007). Code of the Infancy and the Adolescence. Commented Version. http://es.scribd.com/doc/258209685/codigo-de-infancia-y-adolescencia-comentado 
National Institute of Statistics_-INE (2011) Review of the Municipal Poll. http://www.ine.es

Observatory of Matters of Kind (2004). The Family: Reflections, Numbers and Legislation on Violence Intrafamily. Bogota: Presidential Council for the Equity of the Woman.

PDH (2004). Attorney of the Human Rights_-Violent Deaths of Childhood, Adolescence and Young Women and Offers for His Prevention. Ciudad de Guatemala: PDH.

Ramo, C., \& Meléndez, I. (2012). Teenagers Emigrants from the Statement to the Singularity. Zaragoza: Mira Editores.

Rico, A. (2001). Family, Kind and Urban Poverty in Colombia: Survival and Future. Magazine Political Paper, 13, 115-135.

Rodríguez, J. (2009). Teen Reproduction and Lack of Equality in Latin America and the Caribe: Called the Reflection and the Action. Madrid: OIJ, CEPAL, UNFDA.

Santacruz, G. et al. (2001). Neighborhood I Enter: The Solidarity Forces of the Gangs. San Salvador: IUDOP.

Sohrabi, F., \& Hasani, A. (2007). Parenting Styles and Anti-Social Behaviors of Female Adolescents. Journal of Psychology, 11, 74-88.

Soriano, J. (2008). Social Adjustment of the Juvenile Latin-American Gangs in Spain: Gangs and Juvenile Organizations: Two Different Worlds. Magazine CIDOB D’afers Internacionals, 81, 109-137.

Visión Mundial Internacional (2001). Faces of Violence in Latin America and the Carib. Costa Rica: World International Vision. 